\title{
Appeal to Ecologists and All Involved in Environmental Conservation*
}

We, the whole of humankind, live in a troubled time. The fundamental human right - the right to live - is now threatened. We address you at this time with the sincere and deep conviction that by means of united efforts we will be able to accomplish much for the good of humankind, for the peaceful future of the nations of the world, and for all life on Earth.

The three-ways' interaction among individuals, society, and Nature, is becoming ever-more complex and discordant. And all of us well know the consequences of that: a deterioration of human health, a threat to the very existence of the human species, and a menace to all life on Earth.

The danger of ecological crisis has achieved global dimensions. Among the major obstacles to achieving a sustainable dynamic balance among individuals, society, and Nature, are: the agricultural and other resource-demands of a global population that is already immense and still increasing; the growing levels of global air and water pollution that compromise human health and at the same time debilitate the Earth's great bioproductive systems; and the increasingly heavy human exploitation, beyond their ability to regenerate, of the world's renewable natural resources.

Added to the above threats is the heavy burden of existing military conflicts, of the nuclear arms-race, of the militarization of space, and of all the other military expenditures. These today devour vast financial, material, and intellectual, resources. The military sector of society represents some $5 \%$ of the gross global product, and utilizes at least that fraction-and often two to three times that fraction-of our natural resources. Whereas one-quarter to one-third of all scientists and engineers in the world are now engaged in military pursuits, dramatically fewer are engaged in environmental protection or ecological pursuits. In today's grave state of ecological affairs, these resources should rather be used for the restoration, maintenance, and improvement, of the human environment.

Great environmental changes have already been made in a shorter time than ever before in the history of the Earth. In the event of nuclear warfare, with its numerous destructive effects-including the newly-recognized nuclear winter-all living things on Earth would be subjected to the greatest irreversible catastrophe in the history of our globe.

The problems involve a new ecological understanding that penetrates all traditional areas of the sciences and humanities. Their evaluation requires an open-minded and independent approach, unfettered by older constraints, to face the reality about what is happening. Ecological scientists throughout the world cannot remain indifferent when the future integrity of the human environment and the very existence of the human species are at stake. It becomes their duty to intensify and unite their efforts in the struggle for a healthy Biosphere in a peaceful world. The traditional research and educational functions of ecologists must be supplemented by an active involvement in the public and decision-making arenas in the realm of environmental protection against over-exploitation and misuse of natural resources, against ecological degradation by air and water pollution, and against the threat to life of nuclear and other weapons of mass destruction. They must strive for reduction in military efforts and expenditures in favour of those for environmental improvement and human betterment. Moreover, ecologists must enlist the help of other scientists throughout the world in the campaign for peace. Time is not on our side.

We, the participants in the Conference on 'Man and Nature', organized by the Bulgarian National Committee for the Protection of Nature, appeal to you, our colleagues, scientists from all countries, to unite in our efforts towards solving our global ecological problems within the necessary framework of a peaceful world. There are no frontiers that separate those who strive for these noble aims.

Arthur H. Westing, * Senior Research Fellow

Stockholm International Peace Research Institute (SIPRI) Bergshamra, S-17173 Solna, Sweden.

\begin{abstract}
* Submitted on behalf of the 26 Conference participants, ecologists and environmental scientists from 12 countries, who all signed this document on 19 September 1984 in Varna, Bulgaria. They were: Carl Amery (Munich, Fed. Rep. Germany), Mary Jane Amery (Ibid.), Dr Nansen Behar (Sofia, Bulgaria), Georgi Dimitrov-Goshkin (Sofia, Bulgaria), Georgi Djolov (Sofia, Bulgaria), Academician Ivan T. Frolov (Moskow, USSR), Nikolay Georgiev (Sofia, Bulgaria), Dr Pavel Georgiev (Sofia, Bulgaria), Dr Salien Ghosh (Delhi, India), Peter Guerassimov (Sofia, Bulgaria), Nedyalko Hristov (Sofia, Bulgaria), Professor Dr Assen Katov (Sofia, Bulgaria), Dr Kola Kusemiju (Lagos, Nigeria), Professor Vincent Labeyrie (Pau, France), Dr Tapio Lindholm (Helsinki, Finland), Francesca Loening (Edinburgh, UK), Professor Ulrich E. Loening (Edinburgh, UK), Professor Dr Simeon Nedyalkov (Sofia, Bulgaria), Prof. Dr Imre Nagi (Budapest, Hungary), Vesselin Neykov (Sofia, Bulgaria), Dr Johannes B. Opschoor (Amsterdam, Netherlands), Dono Petrov (Sofia, Bulgaria), Professor Radi Radev (Sofia, Bulgaria), Dr Peter A. Schmidt (Tharandt, German Dem. Rep.), Petja Tchoneva (Sofia, Bulgaria), and Professor Arthur H. Westing (Stockholm, Sweden).
\end{abstract}

\section{Global Population: Bright Flashes on a Dark Horizon?}

It would be a dangerous mistake to rejoice at the falling world 'fertility rate', experts warn. Although the current rate of human population increase is $1.7 \%$ a year, compared with $2 \%$ a decade ago, today's population is considerably larger, such that there will in fact be more babies born this year than in 1974 .

Much of the progress in lowering fertility rates comes from only one nation, China, where the annual rate of increase has halved over ten years to $1.2 \%$. But UN projections that world population could stabilize at 10.2 thousand millions around the year 2100 , assume declining rates in nations which show no such signs.

However, there is room for some hesitant optimism. The belief that countries must dramatically improve their economies before fertility rates fall, is misconceived; for although it is often true, there are some notable exceptions to this supposed rule.

The World Bank's 1984 World Development Report points to China, where population planning depended less on GNP than on public education, social pressure, and economic "sanctions' for large families. Public education has also played a key role in Sri Lanka, Indonesia, and parts of India. Moreover, fertility has fallen faster in Colombia and Tunisia, where the governments have long supported family planning, than in wealthier Brazil and Algeria.

The World Bank draws two conclusions. First, that fertility decline in the Third World has been related not to industrial growth but to education, health, and the alleviation of poverty. Second, 'where family planning services are widespread and affordable, fertility has declined more rapidly than social and economic progress alone would predict'.

The World Bank's report shows that even poor nations have no excuse for runaway population growth.

LLOYD TIMBERLAKE \&

DONATUS DE SILVA

Earthscan

3 Endsleigh Street

London WCIH ODD

England, UK. 